\title{
Um clássico entre nós: Augusto Luiz Nobre de Melo
}

Maurício Viotti Daker ${ }^{1}$

\section{Resumo}

Nobre de Melo vivenciou época em que aspectos conceituais e filosóficos enriqueciam de modo marcante a psiquiatria, mostrando especial apreço pela fenomenologia e análise existencial. É autor do tratado "Psiquiatria", de cerca de mil páginas, dentre elas quase trezentas sobre os fundamentos conceituais da psicologia, psicopatologia e psiquiatria. Faremos leituras introdutórias do tópico "Ciência e Filosofia" e do capítulo "Fenomenologia e Análise Existencial em Psicopatologia". Neste serão focadas as ideias de Husserl e de Heidegger, assim como abordados os conceitos de compreender e explicar, e mencionados os métodos fenomenológicos em psiquiatria.

Palavras-chave: Psicopatologia; Filosofia; Fenomenologia; Existencialismo.

\section{A classic among us: Augusto Luiz Nobre de Melo}

\begin{abstract}
Nobre de Melo lived a time when conceptual and philosophical aspects markedly enriched psychiatry, showing a special regard for phenomenology and existential analysis. He is the author of the treatise "Psychiatry", with about a thousand pages, among them nearly three hundred on the conceptual foundations of psychology, psychopathology and psychiatry. We make introductory readings on the topic "Science and Philosophy" and the chapter "Phenomenology and Existential Analysis in Psychopathology". In this chapter will be focused the ideas of Husserl and Heidegger, as well as considered the

1 Professor Associado do Departamento de Saúde Mental da FM-UFMG. Doutor em Medicina/Psiquiatria pela Universidade de Heidelberg (CAPES/DAAD). Coordenador do Grupo de Investigação em Psicopatologia Conceitual, FM-UFMG. Email: viotti@ymail.com
\end{abstract}


concepts of understanding and explaining, and mentioned the phenomenological methods in psychiatry.

Key-words: Psychopathology; Philosophy; Phenomenology; Existentialism.

\section{Introdução}

A psiquiatria, do ponto de vista científico, está atrasada em relação às outras especialidades médicas. Certo ou errado? Atualmente, como em outras épocas, essa asserção com conotação de certeza científica não se aplica de modo claro e tão convincente. Depende, antes de tudo, do que se entende por ciência, isso atrelado ao grau de complexidade do campo em questão. Assim, considerase a psiquiatria, hoje, campo mais complexo que as demais especialidades médicas, exatamente por envolver diretamente a mente: a pessoa imersa na história, na cultura, na linguagem. São áreas dificilmente abarcáveis por meio da ciência hard tradicional, mas com as quais a psiquiatria tem que lidar. A medicina em geral, por lidar com o homem, também terá que se aprofundar nisso. Portanto, a psiquiatria se encontraria, sim, mais avançada, na vanguarda desse essencial fundamento médico (Fulford, 2004; Fulford, Morris, Sadler, Stanghellini, 2003; Maj, 2010; Philips, 2004).

Nobre de Melo vivenciou uma dessas épocas em que relevantes aspectos inerentes à mente e às ditas ciências humanas se expandiu: o pós-guerra. Percebe-se esse veio humanista ante a vasta literatura empregada em seu tratado "Psiquiatria" (Melo, 1970, 1979, 1981). Após as desastrosas certezas "científicas" com fúnebres (literalmente) consequências para os inocentes doentes mentais (Rotzol et al, 2010), valorizaram-se novamente tais aspectos humanos em psiquiatria, por meio especialmente da psicanálise e da fenomenologia e existencialismo. A primeira, com ampla penetração ao redor do mundo, e a segunda, centro-europeia e em parte do mundo latino. Entre ambas as orientações, percebe-se o maior apreço de Melo pela fenomenologia e existencialismo: "Tal influência, nestas últimas décadas, tem sido, sob certos aspectos, não somente comparável, mas até mesmo superior à da Psicanálise" (Melo, 1981, p. 119).

Nesta leitura de sua editio princeps, o tratado de psiquiatria, selecionaremos o tópico "Ciência e Filosofia", acrescido de considerações sobre 
a psicologia, psicopatologia e psiquiatria, e o capítulo "Fenomenologia e Análise Existencial em Psicopatologia"2.

\section{Ciência e filosofia}

A íntima relação entre filosofia e ciência é enfatizada. Seus fins seriam os mesmos: tudo que exista de acessível, no campo da realidade, às sondagens da razão e da experiência. Porém, diferem-se metodologicamente. Ainda que o objetivo da ciência tenha passado do "porquê" das coisas (Aristóteles) para o "como" (Renascimento), persistiu o abismo entre o homem e as coisas em função das limitações dos nossos sentidos e da disjunção sujeito-objeto. Refere Melo:

se a aparência do mundo não traduz a verdadeira natureza das coisas, então o conhecimento científico não pode restringir-se a uma simples transcrição fiel e concreta de dados objetivos, apreendidos, tão-somente, através das vigias embaçadas e nevoentas do nosso sensório... Conhecer significa, antes de tudo, saber distinguir e relacionar. Quer isso dizer, por conseguinte, que há em todo processo de conhecimento sistemático uma operação prévia de análise que o espírito realiza, obrigatoriamente, para surpreender a ordem subjacente e tentar descobrir a causalidade material do mundo. (Melo, 1981, p. 44)

A filosofia exerceria função normativa e valorizadora dos dados da experiência, coordenando e correlacionando as verdades parciais ou relativas, postas em evidência pelas diversas ciências particulares, em seus respectivos territórios de investigações. Há em toda ciência uma mundividência ou Weltanschauung, que a obriga à tomada, consciente ou inconsciente, de uma posição filosófica ante o objeto investigado. Quando inconsciente, tratar-se-ia de uma Weltanschauung que ignora a si mesma, como no caso daquele cientista que ostenta menosprezo pela especulação filosófica: a própria proclamação da supremacia da investigação empírico-objetiva implica uma "profissão-de-fé metafísica".

Tal mundividência inconsciente corresponderia àquele período ultrapassado da ciência positiva. Para Melo (1981), a ciência moderna busca amparar-se no pensamento filosófico, em seus fundamentos e ensinamentos, para a captação e penetração da realidade, ainda que as ciências particulares

\footnotetext{
${ }^{2}$ Para resenha mais ampla, cf. Daker, M. V. (no prelo): Nobre de Melo: conceitos em psiquiatria.
} 
possam progredir com independência, até certo ponto, em seus setores estritos. Afirma que, embora esse "estupendo movimento de renovação do espírito e da cultura" (Melo, 1981, p. 49) tivesse como ponto de partida as ciências físicomatemáticas, referindo-se ao princípio de incerteza quântica, à teoria da relatividade e avanços semelhantes na matemática,

coube às ciências do homem a posição de vanguarda na consolidação do consórcio fecundo e construtivo, em que hoje se aliam, pacificamente, Ciência e Filosofia. Daí que tenha passado então à Psicologia, que é a disciplina básica de todo grupo, matéria essencial para o conhecimento antropológico, a função de estabelecer e resguardar o enlace, o vínculo, entre as ciências naturais e as ciências culturais, entre a Biologia e a Sociologia, entre a Antropologia e a História, entre a Física e a Metafísica. (Melo, 1981, p. 49).

Wundt reservou em sua classificação das ciências espaço bem definido para as denominadas ciências do espírito, que não sobressaíam em classificações anteriores (Ampère, Comte). Subdividia as ciências em formais (matemáticas puras, servidas pelo método dedutivo) e reais. Estas subdivididas em ciências da natureza (eminentemente empíricas e indutivas) e ciências do espírito ou da cultura. Melo tem como certa a influência em Wundt de Dilthey, no tocante às últimas. Dilthey estabelecera distinção essencial entre o explicar e o compreender (Philips, 2004). Para as ciências naturais, a estrutura puramente explicativo-causal. Para as ciências do espírito, a estrutura eminentemente compreensiva e descritiva. As primeiras pressupõem relações de causa e efeito, ao passo que as segundas conexões de sentido no empiricamente dado, entre fenômenos. Estes, "embora insuscetíveis de explicação causal revelam-se, todavia, passíveis de compreensão com respeito aos valores normativos da cultura" (Melo, 1981, p. 51). Note-se bem, tais valores são criados pelo homem em processo histórico-cultural (vide Hegel), que não dependem diretamente de determinações biológicas, donde inalcançáveis pelo método explicativo das ciências naturais.

\section{Psicologia, psicopatologia e psiquiatria}

Se todas as ciências derivam da filosofia, a psicologia seria uma disciplina filosófica por excelência, pelas complexas e múltiplas questões epistemológicas e ontológicas envolvidas em seu escopo. Não se trata de subestimar seus fundamentos biológicos, mas a psicologia transcende 
largamente a esfera biológica de matiz empírico-positivista. Uma definição adequada da psicologia não é simples. O termo vem de 1590 (Gockel) e substitui o que seria a antiga ciência da alma. A definição de ciência da alma (e o corpo?), assim como a de ciência da consciência (e os afetos, e o corpo?) e de ciência do comportamento (psicologia não-psicológica?) esbarram em dificuldades. Nobre de Melo (1981) prefere a definição para a psicologia de "estudo sistemático das manifestações da vida psíquica normal" (p. 54), considerando a vida psíquica normal tanto em sua estrutura dinâmica quanto em suas expressões corporais. Nesta acepção, subdivide-se nas duas ordens de experiências que constituem objeto de estudo da psicologia: os fenômenos psicofisiológicos elementares e os fenômenos psicológicos propriamente ditos. Os primeiros são diretamente observáveis, sujeitos à experimentação e a análises quantitativas, sendo suscetíveis de explicação causal e, assim, caracterizam a psicologia como ciência empírico-positiva, dentre as ciências naturais. Os segundos são inacessíveis à análise explicativo-causal, mas captáveis por métodos sintéticos de compreensão intuitiva, empática, no âmbito das ciências espirituais ou culturais.

Definida assim a psicologia, Melo (1981) adentra na questão de sua relação com a psicopatologia e a psiquiatria. Indaga se a psicopatologia seria então uma parte da psicologia que se refere às anomalias, deficiências e enfermidades da mente humana. A resposta é negativa, pois requer formação médica. O que empresta à psicopatologia condição de disciplina autônoma é a série de fenômenos especiais que não representam simples desvios quantitativos do normal, são alterações de qualidade extremamente variadas e complexas, que não são habitualmente acessíveis ao psicólogo em geral e sim ao médico. Por outro lado, todo médico deve saber psicologia, o que caracteriza os grandes médicos. Nesse sentido, cita Jaspers: "os médicos estarão tanto mais à altura de sua missão, na medida em que saibam ser psiquiatras" (citado por Melo, 1981, p. 57). A psicologia é indispensável ao psicopatólogo, a partir da condição mesma de definir o que é normal e anormal. E a psicopatologia, por sua vez, contribui muito para a psicologia. Por fim, não confundir psicopatologia com psiquiatria. A primeira se restringe ao estudo das manifestações e mecanismos psíquicos anormais, formando conceitos e princípios atinentes ao enfermo da mente enquanto genericamente considerado. Já a psiquiatria volta-se, enquanto especialidade médica, especificamente para o homem enfermo da mente em particular, para o caso clínico, servindo-se da psicopatologia como seu principal instrumento auxiliar. 


\section{Fenomenologia e análise existencial em psicopatologia}

No capítulo "Panorama da Psicologia Contemporânea" são descritas as várias correntes da psicologia, notando-se especial apreço pelo estruturalismo e personalística, assim como pela Gestaltpsychologie. À psicanálise e à fenomenologia e análise existencial são dedicados capítulos próprios. Melo (1981) considera as contribuições fenomenológicas e analítico-existenciais as de maior repercussão na psicopatologia e na psiquiatria, "de mais elevado padrão cultural até hoje consignado nesse território" (p. 119). Alude a que seu conhecimento vinha se expandindo e deixando a exclusividade de uma aristocracia filosófica refinada. No entanto, como sabemos hoje, isso não se concretizou. Devido, em especial, aos formidáveis avanços tecnológicos, propulsores de renovado e produtivo foco empírico e pragmático na psiquiatria, na vertente da biologia e das ciências naturais, que levaram quase à penumbra aquelas discussões de fundamento filosófico mais avançado sobre a mente e a psicopatologia, assim como decaiu o interesse pela psicanálise. Não obstante, o foco na biologia deixa de lado aspectos essenciais do psiquismo humano e suas alterações, razão pela qual é prudente para a psiquiatria, em função de sua própria identidade ou de sua atividade-fim, não abandonar essas questões conceitualmente ricas ora latentes. Alternativamente, nova corrente filosófica tem defendido a necessidade de aprofundamento filosófico por demanda do próprio progresso científico em medicina, que descortina opções envoltas em valores culturais e éticos (Fulford et al, 2003; Fulford, Thornton, Graham, 2006).

Ante a complexidade dos conceitos envolvidos no capítulo em questão, não se deve esperar a facilidade de entendimento que se encontra usualmente em livros-texto. E lembremos que as concepções dos próprios filósofos mudam ou avançam ao longo de suas obras. Aparentemente, uma imersão profunda nesses conhecimentos requer dedicação vitalícia, inclusive, em se tratando de psicopatologia, boa prática com os transtornos mentais. Procuraremos traçar, resumidamente e, esperamos, em linhas pouco tortuosas, noção do rico conteúdo que o autor nos reserva. ${ }^{3}$

\footnotetext{
3 Auxilia-nos também material dos cursos "Psicopatologia Fenomenológica e Psicoterapia Existencial" e "Medicina e Filosofia: Discutindo e Compreendendo o Humano", coordenados pelo autor e por Roberto Ernesto Schmidlin na Faculdade de Medicina da UFMG.
} 


\section{Husserl}

O termo "fenomenologia" (phainomenon deriva do verbo phainesthai, aquilo que se apresenta ou se mostra; logos, estudo) significa o estudo da aparência. Foi empregado nessa acepção, primeiramente, por Lambert, em 1764. Anos depois, sem referência a esse autor, por Kant. De modo diverso o empregou Hegel em sua Fenomenologia do Espírito, de 1807, em que designa o conjunto das manifestações totais da vida do espírito, imbuída do devir humano enquanto ente histórico, na consciência ou experiência do mundo. Coube a Husserl, no início o século passado, a conceituação da fenomenologia como novo modo de conceber e abordar os problemas filosóficos e científicos, o que representou reação à pretensão positivista de eliminar a metafísica das ciências e ensejou ampla difusão do termo. A rigor, segundo Nobre de Melo (1981), Husserl combatia o empirismo ingênuo, pretensioso, e se empenhou em oferecer instrumento metodológico - o método fenomenológico - rigoroso e adequado para que inclusive os empiristas pudessem alcançar mais alto nível de certeza científica. Note-se que Husserl possuía boa formação e interesse em matemática, tanto que seus primeiros trabalhos foram "Sobre o conceito de número" e "Filosofia da aritmética", era afeito à objetividade e à lógica. Desiludira-se, em seus primeiros trabalhos, com a capacidade da psicologia e da consciência explicar logicamente a ciência - a filosofia fora minimizada a uma psicologia científica vinculada ao positivismo (psicologismo) - e centrou suas ações na lógica como disciplina filosófica autônoma. Em sua crítica contra o psicologismo, insistiu que os princípios lógicos teriam validez objetiva, ou seja, que se refeririam a algo verdadeiro ou não, independentemente de como o psiquismo o processa ou pensa.

Husserl acalentava, com isso, o propósito de vir a fundar uma nova Ciência ou Filosofia Primeira, que lhe permitisse estabelecer nexo unitário entre todas as ciências, espécie de novo organum, capaz de fornecer-lhe a chave da almejada relação entre a 'subjetividade do conhecer e a objetividade do conhecimento'. (Melo, 1981, p. 161)

Aceitará os conceitos de totalidade, estrutura, significação e compreensão de Dilthey (rejeita o historicismo de valores relativos, portanto incapaz de alcançar o rigor requerido por uma ciência genuína), assim como refunde e incorpora a nomenclatura de Kant (rejeita o idealismo transcendental). Chega a admitir-se um neocartesianista, ou melhor, o cogito cartesiano seria o "ponto de partida radical" indispensável à execução de sua tarefa, mas sem recurso à 
dúvida e ao Deus (perfeição) cartesianos. Inaugura, assim, a fenomenologia pura ou transcendental, alicerce de uma psicologia fenomenológica.

Por Psicologia Fenomenológica sensu strictu, Husserl designa uma psicologia pura, descritiva, apriorística, baseada na apreensão intuitiva dos fenômenos psíquicos, tais como se dão na consciência, isto é, tais como são experimentados, e dentro dos limites em que o são. Essa descrição, dita eidética, exige, para efetuar-se, a prévia depuração do que nos é facultado captar na atitude natural, operação a que se dá o nome de redução (epochê), e que tem por fim evidenciar, por sobre todas as singularizações e variações possíveis e imagináveis, o que há de estável, geral, permanente e característico, nos fenômenos em referência, vale dizer - o que há de essencial no suceder anímico. Para atingir esse objetivo, isto é, para fazer emergir o eidos, a essência (Wesen), há que adotar uma postura de espírito especial, a chamada - atitude fenomenológica, graças à qual o mundo natural é colocado 'entre parêntesis' . (Melo, 1981, p. 162-3)

Enquanto que o dubito cartesiano resultaria em negação do mundo, a redução de Husserl contempla os objetos do mundo captados sensorialmente e tudo mais que pertence ou provém do mundo, inclusive o próprio eu, axiomas matemáticos e juízos de existência e de valor. Mediante a redução ou epoché, pode-se abordar os dois polos da experiência, noema ou polo do mundo, do objeto ou do outro, e noesis ou polo do eu, de modo a reduzir ou depurar o noema a sua forma essencial. Essa correlação entre noesis e noema forma uma totalidade unitária que liga o ser ao seu ambiente e, portanto, supera a relação dual sujeito-objeto.

Essencial é aquilo sem o quê o fenômeno não é mais o mesmo, como, por exemplo, os três ângulos do triângulo, sem os quais não há triângulo. Pode-se dizer que é a verdade objetiva do fato subjetivo, ou seja, o noema (na correlação noético-noemática) e não a coisa em si propriamente. E esses fatos subjetivos ou mentais não são puramente individuais (isso resultaria no solipsismo), pois há e é necessário um ego comum (como já constava em Kant) ou um mundo em coexistência, que dividimos em intersubjetividade. Isso é atrelado à intencionalidade da consciência, ou seja, ao fato de que a consciência visa sempre ao mundo ou às coisas (é inerente à correlação noético-noemática). $\mathrm{O}$ que se pretende com a redução fenomenológica é descrever o objeto tal como ele aparece para todos. Esse ego comum, transcendental, e o significado do percebido serão elaborados como construção no tempo, em processo históricocultural (inclui a linguagem). 
Quanto à apreensão intuitiva, vale dizer que ela difere da abstração ou generalização do método indutivo. Este busca os antecedentes causais dos diversos dados empíricos, enquanto que a intuição eidética é o dar-se conta das essências ou das estruturas essenciais (Wesensschau), do significado do que foi percebido na experiência vivida. Em outras palavras, o significado é como algo se dá para a consciência e deve ser intuído e não construído de modo abstrato. A intuição é ancorada à experiência vivida (esta é pré-reflexiva, anterior e mais fundamental que a consciência) e a ênfase dada a ela por Husserl implica que sua fenomenologia não é uma filosofia meramente especulativa. Daí sua célebre frase: "ir diretamente às coisas mesmas", porém enquanto noema na correlação noético-noemática, e não a coisa em si sem a (inevitável) participação da mente.

Trata-se a fenomenologia de nova orientação para a investigação da realidade psíquica, isenta de pressupostos teóricos e eminentemente compreensiva e descritiva. Coube a Jaspers introduzir na psiquiatra o modo de pensar fenomenológico, com múltiplas ramificações em vários centros e grande desenvoltura onde ele atuou, a escola psiquiátrica de Heidelberg - Wilmanns, Gruhle, Mayer-Gross, Kurt Schneider e outros (Eming \& Fuchs, 2008). Max Scheler foi igualmente um dos pioneiros a utilizar o método fenomenológico husserliano, em seus conhecidos estudos sobre os sentimentos, além de em sua antropologia filosófica. Ampliou, assim, a ideia de intuição, colocando, ao lado de uma intuição intelectual, outra de caráter emocional. Não que tais autores abdicassem do método indutivo, mas o uso da intuição de essências possibilita uma nova abordagem mais refinada de se fazer ciência em psicopatologia.

\section{Heidegger}

A fenomenologia de Husserl desemboca diretamente, segundo Melo, na "analítica existencial" (Daseinsanalyse), denominação que Heidegger deu à sua filosofia existencial. Heidegger aplicou o método fenomenológico de seu mestre, com variações, ao estudo e análise da existência do homem. Os horizontes são ampliados, ser lançado no mundo e na contingência de realizar projetos implica um tipo de intencionalidade muito mais fundamental que a intencionalidade de contemplar objetos, de que especialmente se ocupava Husserl.

Heidegger entendeu que para poder responder à questão sobre o sentido de ser, que era seu objetivo, teria antes que elucidar o ser que pergunta pelo ser: o homem. A metafísica teria sido dominada, desde Parmênides, pela concepção 
de que o ser é imutável, permanente, constante. Heidegger rompe com essa noção milenar e retorna a Heráclito, no tocante ao caráter mutável no tempo do mundo sensível. Em outras palavras, ser pode ser entendido em sua acepção mais estática, propriamente como o termo "ser", ou mais dinâmica e passageira, "estar". Estar em alemão é Dasein. Dasein é a designação do ser humano no livro "Ser e Tempo", não mais consciência. Heidegger considera que, antes de sermos consciência, somos presenças ou existências, termos igualmente contemplados pela palavra Dasein, sendo a consciência um modo parcial possível da presença. Dasein implica imersão no mundo (não se pode conceber a presença sem mundo, pois então ela já não seria mais presença), mundo do homem, ser-nomundo. E a sincronia com esse mundo implica movimento, constante transformação. Dasein é devir. Em vez da objetividade e distância científicas, movemo-nos dentro desse mundo, cuja condição é a do devir, sempre o temos como provisório, como processo.

Em Ser e Tempo, estes se equivalem: é vir a ser. A presença é ser de abertura para possibilidades, umas em detrimento de outras. Não podemos ser perfeitos na completude de todas. Para uma existência autêntica, teremos que aceitar muitas "mortes" das possibilidades não realizadas, até a inevitável morte final concreta. A angústia é inerente ao homem em nosso ser-para-amorte. Negar isso leva a uma existência inautêntica. Relevante, em especial para a psicoterapia, é a "liberdade para a morte" ou o corolário sartriano "condenado a ser livre" (em tons mais amenos ou otimistas em outros autores: amor em Binswanger, dimensão espiritual em Frankl), que implica a característica capacidade do ser humano de antecipar seus projetos, de liberdade de escolha ante seu destino. E não mais se discute, na terapia, apenas a estrutura individual do paciente, mas igualmente o mundo que ele constitui, como o experimenta, lhe dá sentido e contornos, ou seja, as características de seu ser-no-mundo, sob diversas perspectivas (temporalidade, espacialidade, corporalidade, mundaneidade, intersubjetividade ou encontro, etc.).

Posteriormente, Heidegger concluirá que o ser não se dá propriamente à presença, que esta seria apenas uma clareira, uma abertura aos entes que primariamente se desvelam. Para tanto, para que esses entes se desvelem no homem singular (na presença ou ente-clareira), é necessária uma coletividade, uma intersubjetividade, uma linguagem. Implica uma história e cultura, cujas experiências são cristalizadas na língua, por meio da qual o ente se desvela, "é falado“. Sem coletividade e sem linguagem não há ser. Por isso, Heidegger não teria levado adiante novas edições relacionadas a Ser e Tempo, pois o ser não se encontra na presença ou existência humana. Mas não é qualquer linguagem que exprime o ser. Sim, sobretudo, na poesia. Para Heidegger, a linguagem matemática e a linguagem científica possibilitam expressão mais limitada do 
ser. Nestas, há adequação mais estrita à coisa ou matéria, à facticidade e objetividade (transcendência espontâneo-receptiva). Naquela, mais liberdade e criatividade para novas configurações (transcendência espontânea). Já na linguagem do delirante, a título de comparação, haveria grande deficiência na transcendência e na espontaneidade, quase que mero registro receptivo das coisas.

\section{Compreender e explicar}

Voltemos agora à compreensão e à explicação, atitudes metodológicas fundamentais. No psíquico como um todo unitário, dinamicamente estruturado e integrado, o fato típico fundamental é a vivência ou experiência interna vivida, ou seja, tudo o que transcorre continuamente, a cada instante, no âmbito subjetivo da consciência individual. Tais vivências são suscetíveis de diferentes modos de captação e compreensão:

- Captação intuitiva e compreensão estática: foco em uma descrição clara e exata da experiência vivida com base na intuição husserliana e seu método fenomenológico, devemos nos abster de explicações e de correlações genético-motivacionais.

- Compreensão dinâmica ou genética: aqui já se procuram motivos psicológicos no encadeamento dos acontecimentos psíquicos, que não se tratam de relações de causa e efeito ou explicação como no mundo natural.

- Compreensão "como se...": seria em analogia, fictícia, ainda assim poderia ser útil em alguns casos.

- Compreensão penetrante: seria a compreensão de elementos no bojo de uma estrutura complexa, em um todo a que se subordinam.

- Compreensão intelectual e racional: é a única de que se ocupa a psicologia empírico-natural e não constitui compreensão psicológica propriamente e sim uma atividade intelectual.

- Compreensão existencial ou categorial: aqui a compreensão psicológica esbarraria no limite do incompreensível,

converte-se em 'esclarecimento da existência' (Jaspers), levandonos então a apelar para toda espécie de conceitos metafísicos (a liberdade, a decisão, o nada, a morte, etc.), em função dos quais se interpretam os modos disponíveis de existência individual, em suas relações de significado oculto ou inaparente com as situações e elaborações existenciais possíveis. (Melo, 1981, p. 171) 
Toda compreensão em sentido psicológico ou existencial é sempre eminentemente empática. A compreensão meramente intelectual representa nada mais que um meio de conduzir à sondagem profunda e à penetração real na vida anímica, esta somente possível por ressonância empática. Por outro lado:

O fenômeno que se nos mostra psicologicamente incompreensível passará a ser então explicável mediante a construção de hipóteses e teorias, destinadas à sua interpretação, e que nos poderão ser tanto mais úteis, claro, quanto melhor comprovem sua validez ou plausibilidade, na concatenação lógico-formal de seus pressupostos. (Melo, 1981, p. 171)

O limite à compreensão é estímulo à interrogação causal, incentiva a descoberta e explicação.

Neste ponto, vale lembrar que em psiquiatria não lidamos geralmente com fatos consumados, conhecidos ou bem delimitáveis em suas causas e manifestações. Donde a relevância, além do método compreensivo, da "construção de hipóteses e teorias", de concepções bem embasadas. Entende-se, assim, o predomínio tradicional, em psiquiatria, de ideias em relação ao de descobertas. A questão ou especial complexidade em psiquiatria seria como explicar, por via empírico-objetivo-causal, por partes, "um todo dinamicamente estruturado e integrado", incluída aí a intersubjetividade ou sociabilidade. O organismo físico é facilmente decomponível em partes bem delimitadas e acessíveis aos métodos naturais. Já a mente, enquanto "totalidade da pessoa humana", não (possivelmente, a noção de sistemas complexos melhor se aproxime da realidade mental). Como diriam eminentes psicopatólogos, o trato com o homem requer algo mais do que o conhecimento científico natural pode dar.

\section{Métodos fenomenológicos}

\footnotetext{
Quanto aos métodos fenomenológicos em psiquiatria, delimita Nobre de Melo:

- O método fenomenológico propriamente dito: refere-se basicamente ao abordado acima sobre Husserl.

- Posições filosóficas e pesquisas psicopatológicas, oriundas e subsidiárias da fenomenologia husserliana: são abordados, especialmente, os sentimentos sensoriais, vitais, psíquicos e espirituais de Max Scheler, os valores materiais, vitais, anímicos e espirituais de Nicolai Hartmann, a
} 
análise do ato intencional de Kronfeld e o modo típico de execução da consciência de Carl Schneider.

- Fenomenologia de Jaspers e suas repercussões psicopatológicas: seu método seria relativamente menos ambicioso e especulativo que de outros fenomenólogos, porém mais exato. Primordial é delimitar, distinguir, precisar e apresentar com a maior exatidão os fenômenos. Adota o método explicativo-causal em conjunção com o compreensivomotivacional-empático, de onde deriva noções como processo, fase, desenvolvimento e reação, forma e conteúdo, bem como distingue sintomas primários de secundários, ideias delirantes de deliroides.

- Fenomenologia antropológica: já com influência de Heidegger (ver acima), não se limita à consideração das experiências subjetivas do enfermo, como vivenciadas e comunicadas, concentrando-se na estrutura antropológica fundamental que as envolve. Observa-se expansão do método compreensivo, como a inibição do devir subjetivo na tristeza vital e em abordagens do delírio, obsessões, fuga de ideias e outros sintomas ou síndromes. Abordada a consideração constitutivo-genética de von Gebsattel, o método fenomenológico-estrutural de Minkowski e a Daseinanalyse ou análise existencial de Binswanger, dentre outros. Acentua-se a possibilidade de se oferecer uma abertura para que o paciente saia de sua situação e refaça seu projeto de mundo, busque sua autenticidade e se restabeleça estruturalmente em sua existência. A exclusividade e rigidez de um só projeto pode ser aquilo que traduz o traço antropológico definidor de desordens psíquicas, estas, por seu turno, reveladoras de um estar-no-mundo alterado, de que os sintomas aparentes não são mais que o produto terminal. A história individual ou biografia, nesse sentido, é enaltecida na análise existencial:

É o Homem, efetivamente, um ser único e sui generis, no meio cósmico, onde desfruta o privilégio de uma posição própria e inconfundível, como possibilidade aberta, em incessante devenir. Sendo, pois, não apenas 'instinto' e não somente 'espírito' é, por excelência, um ser 'abrangente' (Jaspers), isto é, um ser que se define, simultaneamente como - natureza, cultura, consciência, razão, existência, liberdade. (Melo, 1971, p. 220) 


\section{Referências bibliográficas:}

Daker M. V. (no prelo). Revisitando Nobre de Melo: conceitos em psiquiatria. In: Rodrigues A. C. T., Streb L. G., Daker M. V., Serpa O.D. (orgs.) Psicopatologia Conceitual I. Rio de Janeiro, São Paulo: Grupo Editorial Nacional.

Eming K \& Fuchs T. (2008). Karl Jaspers - Philosophie und Psychopathologie. Heidelberg: Universitätsverlag Winter.

Fulford B. (2004). Facts/values. In Radden J. (org.) The Philosophy of Psychiatry (pp. 205-234). Oxford, New York: Oxford University Press.

Fulford B., Morris K., Sadler J., Stanghellini G. (2003) Nature and narrative, an introduction to the new philosophy of psychiatry. Oxford, New York: Oxford University Press.

Fulford B., Thornton T., Graham G. (2006). Oxford Textbook of Philosophy and Psychiatry. Oxford, New York: Oxford University Press.

Maj, M. (2010). Are psychiatrists an endangered species? Editorial. World Psychiatry, 9 (1), 1-2.

Melo A. L. N. (1970). Psiquiatria (1 ${ }^{\mathrm{a}}$ ed.). Rio de Janeiro: Editora Civilização Brasileira.

Brasileira. - (1979). Psiquiatria (2a ed.). Rio de Janeiro: Editora Civilização - (1881). Psiquiatria (3 ${ }^{\mathrm{a}}$ ed.). Rio de Janeiro: Editora Guanabara

Koogan.

Philips J. (2004). Understanding/explanation. In Radden, J. (org.), The Philosophy of Psychiatry (pp. 180-190). Oxford, New York: Oxford University Press.

Rotzoll M., Hohendorf G., Fuchs P., Richter P., Eckart W. U., Mundt Ch. (2010). Die nationalsozialistische "Euthanasie" - Aktion T4 und ihre Opfer - Geschichte und Ethische Konsequenzen für die Gegenwart. Paderborn, München, Wien, Zürich: Schöningh. 